\title{
The Dimensionality of Teacher Collegiality and the Development of Teacher Collegiality Scale
}

\author{
Madiha Shah \\ Faculty of Education, University of Malaya \\ 50603, Kuala Lumpur, Malaysia \\ Tel: 60-17-668-4735 E-mail: madihashah.phd@gmail.com
}

Received: September 13, 2011 Accepted: October 30, 2011 Published: November 15, 2011

doi:10.5296/ije.v3i2.958 URL: http://dx.doi.org/10.5296/ije.v3i2.958

\begin{abstract}
This paper reports on the development of a teacher collegiality scale (TCS) which was validated using a sample of public secondary school teachers in Pakistan. The TCS measures seven dimensions of collegiality: Demonstrating mutual support and trust; observing one another teaching; joint planning and assessment; sharing ideas and expertise; teaching each other; developing curriculum together; and sharing resources. The initial 66 item scale was refined using both exploratory and confirmatory factor analyses. Exploratory factor analysis (EFA) was applied to data from a sample of 118 public secondary school teachers from six schools in Karachi and Lahore. To further validate the scale, confirmatory factor analysis (CFA) was applied to a sample of 364 public secondary school teachers from 17 schools in Islamabad. Based on the CFA results, the scale's items were modified. Analyses found that the 7-dimension scale consisting of 32-items was appropriate for measuring teacher collegiality among Pakistani school teachers. The reliability coefficients of the TCS dimensions ranged from .71 to .85 .
\end{abstract}

Keywords: Teacher collegiality, Scale validation, Secondary schools, Teachers, Pakistan 


\section{Introduction}

The pressure for educators to collaborate has been consistently highlighted as crucial to educational change and success. The traditional image of school teachers working independently and all alone in their classroom with closed doors is no longer relevant. A high level of collegiality among staff members is associated with successful and effective schools (Fullan \& Hargreaves, 1991; Gossen \& Anderson, 1995; Telford, 1996). Recent researchers and educational scientists have suggested that developing the ability of school personnel to function as professional collegial communities may result in substantive school improvement (Barth, 2001; DuFour, 2004; Goddard et al., 2007; Little et al., 2003; Schmoker, 2004). Regrouping teachers and creating new configurations of collaboration and collegiality may be integral to constructive and successful schools (Johnson, 1990). The key to promoting change in schools is to establish a culture based on the principles of collegiality, openness, and trust (Lieberman \& Miller, 1990), for 'schools cannot be improved without people working together' (Lieberman, 1986, p. 6). Schools, recognizing the negative effects caused by psychological isolation (Bruffee, 1999; Heider, 2005), have accelerated their adoption of a collegial approach. Consequently, the practice of teacher collegiality is accepted as essential to professional practice.

The purpose of this paper is to develop and validate a measure of collegiality among school teachers. A valid measure will facilitate research confirming previous findings and support comparative studies. This paper discusses how the teacher collegiality scale (TCS) was developed and the findings of exploratory and confirmatory factor analyses that determined its dimensions and the relevance of each item.

\subsection{What is collegiality?}

Collegiality refers to the cooperative relationships among colleagues; however, its exact meaning remains conceptually vague in the literature. Webster's College Dictionary (1997), defines collegiality as 'sharing responsibility in a group endeavor' and 'cooperative interaction among colleagues' (p. 258). The term is often used interchangeably with 'collaboration'. The American Heritage Dictionary of the English Language (2000, online version) defines collegiality as 'to work together, especially in a joint intellectual effort'. Hargreaves (1994) suggested that there is no such thing as 'real' or 'true' collegiality or collaboration, but many forms of each exists and each serves a different purpose with a different consequence. Hargreaves (1994) further states that the term 'collegiality' is vague and imprecise, and therefore, is open to interpretation.

Smyth (1991) asserted that collegiality is 'not simply a matter of teachers conferring with one another' (Smyth, 1991, p. 325); it is 'much more than a desirable teacher-to-teacher relationship' (Smyth, 1991, p. 327). Campbell and Southworth (1992) suggested that many people use the term as if it is commonly understood, but that understanding generally only means that teachers should 'work together'. Their review of collegiality concludes that 'collegiality is a hazy and imprecise notion' (Campbell \& Southworth, 1992, p. 65). Jarzabkowski (2002), however, tried to differentiate between collegiality and collaboration by 
defining collegiality as teachers' involvement with their peers on any level, be it intellectual, moral, political, social, or emotional. According to her, collegiality encompasses both professional and social interaction in the workplace while collaboration mostly relates to the professional sphere of relationships. According to Lieberman and Miller (1999) teacher collegiality refers to the quality and impact of professional relationships whereby teachers openly and continually investigate and critique school/classroom practice with a view to improvement. Collaboration is seen as a subset of collegiality (Jarzabkowski, 2002; Little, 1999), which implies actually working together on a joint project or towards a common goal.

\subsection{Importance of teacher collegiality}

In any organization there must be a spirit of cooperation among staff members. Such cooperative cultures encourage staff to contribute new ideas, suggestions, and opinions. Staff member feedback is considered and responded to, which in turn makes them feel more committed to the organization. If cooperation and collaboration exist among staff members, the working climate can provide mental relaxation and a cheerful atmosphere, which is a crucial factor in enhancing working efficiency.

Even though a consensus over the definition of collegiality has not yet been reached, collegiality among teachers is considered as essential to school improvement and success (Barth, 2001; DuFour, 2004; Little et al., 2003). The literature shows that the most promising strategy for sustained and substantive school improvement is developing the ability among school personnel to function as professional collegial communities (Goldenberg, 2004; Joyce, 2004). If teachers enjoy working with their colleagues, mutual respect and trust among them develops. In education, collaboration is intended to "promote the most effective teaching possible for the greatest number of students" (Pugach \& Johnson, 1995, p. 178). Expanding the possibilities of instruction supports student learning and improves delivery of curriculum content (Lieberman, 1986). A wider range of demands can be addressed by using a collegial approach than by individual, isolated efforts (Gable et al., 2004).

Strengthening interpersonal relations among teaching personnel is thought to influence a school's professional culture and lead to teachers increasing their involvement and ownership (Andrews \& Lewis, 2002). Collegiality also plays a significant role in improving teaching and instructional practices and fostering innovation (Brownell et al., 2006; Hopkins, Beresford, \& West, 1998; Zhao et al., 2002). Other reported positive outcomes of teacher collegiality include more positive attitudes toward teaching (Brownell et al. 1997), enhanced job satisfaction (Woods \& Weasmer, 2002), reduced stress and burnout (Numeroff, 2005; Maslach \& Leiter, 1999), improved efficacy (Shachar \& Shmuelevitz, 1997), high morale (Nias, 1999), professional growth and development (Hopkins et al., 1998; Knapp, 2003), reduced staff turnover (Abdullah, 2009; Jarzabkowski, 2003), assistance to new and beginning teachers (Wang, Odell, \& Schwille, 2008; Williams, Prestage, \& Bedward, 2001), and increased levels of trust (Tschannen-Moran, 2001).

Collegial activities create a sense of belonging. They provide an opportunity to involve many individuals in solving complex educational problems. Schools that do not support collegiality and allow their teachers to work independently waste human resources and contribute to 
disenchantment with teaching as a career (Zahorik, 1987). McLaughlin (1993) stated that collegial communities in schools create an environment that supports high level of innovation, enthusiasm, and energy among teachers and provides opportunities for teacher professional growth and development.

\subsection{Models and forms of teacher collegiality}

Little (1990) created a model explaining an organization's journey from independence to interdependence. Her model included four forms of collegiality: story telling and scanning for ideas, aid and assistance, sharing, and joint work. Her model captured a continuum ranging from activities that are compatible with teacher independence and autonomy to activities that require interdependent action and the notion of collective autonomy.

She classified story telling and scanning for ideas, aid and assistance, and sharing as less powerful tools in building collegial cultures. Story telling and scanning for ideas was described as an exchange of incomplete stories, complaining, and griping by school staff members. The focus was not on problem solving, nor was it a deep exchange between staff members. Although Little (1990) suggested its contribution to teacher development is limited, she refers to anthropological studies that point to story telling as a means of building a group or providing a form of instruction. Aid and assistance was categorized as the help given to staff members by staff members, but only when asked. Aid and assistance did not allow for evaluation or interference with one another's work; therefore, depth of exchange rarely resulted. Sharing indicated discussions in which staff members engaged, as well as the sharing of resources, ideas, knowledge, and suggestions. Sharing may have led to a change in pedagogy; however, no real work was actually accomplished together.

At the interdependence end of the continuum is joint work, which Little (1990) describes as 'shared responsibility for the work of teaching' and 'a collective conception of autonomy'. She recognized joint work as a strong collegial effort which provides an opportunity for staff members to develop deeper ties to one another and to build more trusting, productive staff relationships. Little (1990) believed that joint work had the greatest potential to build a school-wide culture of collegiality.

In Improving Schools from Within Barth (1990) describes collegiality in more precise terms, he discusses four dimensions of collegiality based on Little's (1982) study. He considers collegiality as a tool through which faculty members grow by learning with and from one another. According to his model, collegiality is the presence of four specific behaviors among school members:

- $\quad$ Adults in school talk about practice. Their conversations about teaching and learning are frequent, continuous, concrete, and precise.

- Adults in schools observe each other engaged in the practice of teaching and administration. Their observations become the practice to reflect on and talk about.

- Adults engage together in work on curriculum by planning, designing, researching, and evaluating curriculum. 
- Adults in schools teach each other what they know about teaching, learning, and leading. Craft knowledge is revealed, articulated, and shared.

\section{Purpose of the study}

The review of literature found that most of the studies on teacher collegiality have used single or multiple case studies. Wheelan and Tilin (1999) assume that these case studies are powerful in helping define the characteristics of effective faculty teamwork, but the studies mostly relied on general observations and discussions with staff to formulate conclusions. The generalisability of these studies' findings is limited. Moreover, no quantifiable measures of collegiality were explored.

The study presented in this paper addressed these limitations. It used the literature to identify the dimensions of teacher collegiality, created indicators, subjected them to expert review, and subjected them to quantitative analysis. Specifically, the Teacher Collegiality Scale (TCS) was constructed and validated using exploratory and confirmatory factor analysis. It was tested using data from public secondary school teachers in Pakistan.

\section{Method and procedures}

The present study was performed in three steps. First, the teacher collegiality scale (TCS) was developed. Second, an initial exploratory study administered the TCS to 118 public secondary school teachers $(61.9 \%$ male and $38.1 \%$ female) from six single-sex secondary schools located in Karachi and Lahore, two major cities in Pakistan. The data were analyzed using exploratory factor analysis (EFA).

Third, the main study was conducted four months later on a sample of 364 public secondary school teachers from 17 single-sex schools (eight male and nine female)(Note 1) in the capital district of Islamabad. These schools were selected randomly. This study was to validate the initial study results. Its data were analyzed using confirmatory factor analysis (CFA) with AMOS 16.0.

To collect the data for the main study, the researcher personally visited the selected schools and met with the principals to discuss the purpose and nature of the study. The principals gave their formal permission for conducting the study at their respective schools. The survey questionnaires along with the cover letter were distributed to the 445 teaching staff members. The cover letter indicated the aim of the research, its significance, and the time required to complete the questionnaire. It assured the participants that the information would be collected independent of their organization, that their participation was voluntary, and that their responses would be kept confidential. A total of 364 (81.8\% response rate) completed questionnaires were collected from the selected schools after a period of two weeks.

\subsection{Development of teacher collegiality scale (TCS)}

The first step in developing the TCS was searching for items in the literature that addressed the collegial practices of school teachers. The main sources were: Little (1982, 1990), Goodlad (1984), Zahorik (1987), Rosenholtz (1989), Barth (1990), Johnson (1990), Nias (1998), Jarzabkowski (1999, 2002), Retallick and Butt (2004), and DuFour (2004). These 
studies were selected because of their thorough and detailed discussions with groups of teachers working in highly collaborative environments.

The initial scale consisted of 66 items gathered from the literature. The scale was sent to five secondary school teachers in Pakistan, who were asked to make suggestions to further improve the scale and identify items needing clarification. Some minor amendments were made based on their suggestions. To confirm the content validity of the scale, the scale was presented to a panel of experts consisting of three faculty members including the study advisor at a public university in Malaysia for their professional judgment and opinion about whether the items were essential, useful or irrelevant to measuring teacher collegiality.

Based on the reviews, some items were dropped from the questionnaire. The resulting 60 -item modified questionnaire was sent to six secondary schools (four male and two female) for data collection in the initial study. Participants were asked to respond to the questionnaire items using 1 to 7 Likert intervals. Response options ranged from 1 (strongly disagree) to 7 (strongly agree), indicating how true each statement was about them.

\section{Results and findings}

\subsection{Initial study results using exploratory factor analysis (EFA)}

EFA with principal component extraction and varimax rotation, was conducted on the data to define the best structure of the set of variables and to identify the dimensionality of teacher collegiality. Principal component factor analysis was chosen because the primary concern was data reduction and acquiring minimum number of factors to account for the maximum portion of the total variance represented in the original set of variables.

Kaiser-Meyer-Olkin (KMO) measure of sampling adequacy along with Bartlett's test of sphericity was conducted to ensure the appropriateness of the data for EFA. KMO measure of sampling adequacy compares the observed correlation coefficients to the partial correlation coefficients. Kaiser (1974) recommends accepting values greater than .5 as acceptable. A KMO value for this data set was .645 which was acceptable and indicated the applicability of EFA.

Bartlett's measure tests the null hypothesis that the original correlation matrix is an identity matrix. For factor analysis to work some relationships between variables are needed. If the $R$-matrix was an identity matrix all correlation coefficients would be zero. Therefore, the result of this test must be significant. The significance test found that the $R$-matrix was not an identity matrix. Bartlett's test for the present study was highly significant $(p<.001)$, and therefore, factor analysis was appropriate for the data set.

Extraction of factors using K1 rule (eigenvalue-one criterion) extraction heuristic indicated a 17 factor solution accounting for $78.63 \%$ of the total variance. To get fewer factors, a scree plot was employed. The scree plot graphs the eigenvalue against the factor number. The scree plot suggested a seven factor solution that would provide the most meaningful and logical interpretation. 
Varimax rotation method was used with Kaiser Normalisation to get the rotated factor matrix. It is a matrix of the factor loadings for each variable onto each factor. Factor loadings show how highly each variable is correlated with the factor. The higher the loading, the more the variable characterizes the factor. A minimum loading of 0.4 was set for any variable used to define a factor. Items with factor loadings less than 0.4 were suppressed and dropped from the analysis. Each item's communality was also taken into consideration to assess if the items met acceptable levels of explanation. The items with communality less than .50 are considered as not having sufficient explanation (Hair et al., 2006). None of the items in the data set revealed a commonality less than .50 . The results of rotated factor analysis are presented in Table 1.

Table 1. Factor loadings for teacher collegiality scale (TCS)

\begin{tabular}{|c|c|}
\hline Factors identified in TCS and its related items & $\begin{array}{l}\text { Factor } \\
\text { loadings }\end{array}$ \\
\hline \multicolumn{2}{|l|}{ Factor 1 (Demonstrating mutual support and trust) } \\
\hline 1. Teachers provide strong social support for colleagues. & .871 \\
\hline 2. Professional interactions among teachers are cooperative and supportive. & .832 \\
\hline 3. There is a feeling of trust and confidence among staff members. & .530 \\
\hline $\begin{array}{l}\text { 4. I can count on most of my colleagues to help me out anywhere, anytime } \\
\text { even though it may not be part of their official assignment. }\end{array}$ & .520 \\
\hline $5^{*}$. Teachers in this school hide their failures and mistakes. & .450 \\
\hline 6. Teachers consider their colleagues as their friends. & .433 \\
\hline $\begin{array}{l}7 * \text { Teachers in this school do not respect the professional competence of } \\
\text { their colleagues. }\end{array}$ & .405 \\
\hline \multicolumn{2}{|l|}{ Factor 2 (Observing one another teaching) } \\
\hline 8. We invite other teachers to observe our teaching. & .836 \\
\hline $\begin{array}{l}\text { 9*. Teachers in this school mind being observed by their colleagues while } \\
\text { teaching. }\end{array}$ & .804 \\
\hline $\begin{array}{l}\text { 10. We regularly observe one another teaching as a part of sharing and } \\
\text { improving instructional strategies. }\end{array}$ & .700 \\
\hline $\begin{array}{l}\text { 11. Most of the teachers in this school are receptive to the presence of other } \\
\text { professionals in their classrooms. }\end{array}$ & .477 \\
\hline $\begin{array}{l}\text { 12. I believe it to be beneficial for my teaching to be open with colleagues } \\
\text { about my successes and challenges. }\end{array}$ & .440 \\
\hline $\begin{array}{l}\text { 13. Feedback received by the colleagues is considered and responded to } \\
\text { appropriately. }\end{array}$ & .412 \\
\hline \multicolumn{2}{|l|}{ Factor 3 (Joint planning and assessment) } \\
\hline 14. Cooperation and collaboration exists across departments. & .728 \\
\hline 15. We jointly plan and prepare teaching strategies and procedures. & .657 \\
\hline 16. Majority of the teachers participate actively in meetings. & .534 \\
\hline $\begin{array}{l}\text { 17. We make collective agreements to test an idea or new approach in } \\
\text { teaching. }\end{array}$ & .515 \\
\hline 18. We jointly accredit new programs and practices. & .464 \\
\hline
\end{tabular}


19. My colleagues and I collectively analyze our teaching practice. 2011, Vol. 3, No. 2: E10

$20 *$. Teachers do not praise or criticize each others teaching.

.431

Factor 4 (Sharing ideas and expertise)

21. We often argue over educational theories, philosophies, or approaches.

Factors identified in TCS and its related items

.813

\begin{tabular}{l|c} 
Factor \\
loadings
\end{tabular}

22. Teachers encourage each other to contribute ideas and suggestions.

.801

23. We often ask each other about classroom management ideas and suggestions.

24*. Teachers in this school do not feel comfortable about discussing their

students' problems.

25. Teachers in this school often ask for suggestions to specific discipline problems.

26. We discuss frequently about school improvement strategies.

Factor 5 (Teaching each other)

27. We often teach each other informally.

28. Teachers in this school enjoy teaching in teams.

29. We feel part of a learning community which values shared responsibility

for ongoing learning.

30. Teachers give demonstrations on how to use new models or strategies.

31. Teachers in this school like to share what they have learned or want to learn.

\section{Factor 6 (Developing curriculum together)}

32. Most teachers in this school contribute actively to making decisions about curriculum.

33. I find time to work with my colleagues on curriculum during a regular work day.

34. Teachers in this school jointly prepare their lesson plans.

$35^{*}$. Teachers in this school feel hesitant in asking for help on specific instructional problems.

\section{Factor 7 (Sharing resources)}

36. My colleagues and I share materials related to my subject teaching.

37. Teachers in this school often lend and borrow materials like worksheets and lesson plans.

38. We often share journal articles and educational books.

Note. Items marked with '*' are reversed scored.

Factor 1 (7-items), was labeled 'demonstrating mutual support and trust' and accounted for $26.09 \%$ of the total variance. Factor 2 (6-items) was labeled 'observing one another teaching' explained $8.07 \%$ of the variance and Factor 3 (7-items) was labeled 'joint planning and assessment' explained $5.38 \%$ of the total variance. Factor 4 (6-items) was labeled 'sharing ideas and expertise' and accounted for $4.94 \%$ of the variance. Factor 5 (5-items) was labeled 'teaching each other' and Factor 6 (4-items) was labeled 'developing curriculum together' 
explained $4.02 \%$ and $3.80 \%$ of the variance respectively. Factor 7 (3-items) was labeled 'sharing resources' and explained $3.50 \%$ of the total variance.

\subsection{Main study results using confirmatory factor analysis (CFA)}

The main study collected data from the sample of 364 public secondary school teachers in Islamabad. The data were analyzed using CFA. The main purpose was to confirm the initial study results. CFA assesses whether observed indicators are loaded on hypothesized latent variables and enables testing of how well the measured variables represent the constructs (Hair et al., 2006).

For the current analysis an initial check of the hypothesized model was conducted to ensure that the number of degrees of freedom associated with the model to ascertain its model identification status. SEM models, both confirmatory factor analytic or structural models, must be over-identified, that is, the number of estimable parameters is less than the number of data points (i.e., variances and covariances of the observed variables), which results in positive degrees of freedom that allow for rejection of the model. The present model was identified with 741 data points or sample moments in the variance-covariance matrix and the number of parameters to be estimated was 97. Therefore, the model was identified with $(741-97)=644$ degrees of freedom.

Regression weights both unstandardized and standardized were estimated. Review of the unstandardized estimates showed that all estimates were reasonable and statistically significant given C.R. values $>1$.96. All C.R. values using a significance level of .05 were greater than 1.96, therefore, considered as significantly different from zero. The Standard Errors (S.E) also appear to be in good order showing no problem with the parameter estimates.

Standardized regression weights of each observed variable onto its latent variable are presented in Table 2 . The standardized regression weights tend to vary between +1 and -1 . The size of the standardized loadings confirms that the indicators are strongly related to their associated constructs and are one indication of construct validity (Hair et al., 2006). Hair and his colleagues (2006) suggested that standardized loading estimates should be at least 0.5 and ideally 0.7 or higher. However, in order to follow the three-indicator rule which suggests at least three indicators/items per scale, only factor loadings less than 0.4 were the candidates for deletion.

Two paths flowing from observing one another teaching (OT) subscale to its Item 3 (OT3 $<---$ OT) and Item 34 (OT34 <--- OT) showed values less than 0.4. Similarly, one path flowing from joint planning and assessment (JPA) subscale to its Item 10 (JPA10<--- JPA) and the other flowing from teaching each other (TE) subscale to its Item 25 (TE25<--- TE) indicated values less than 0.4. Therefore, following Steven's (1996) guideline, all four items (OT3, OT34, JPA10, and TE25) were deleted from their respective subscales. The remaining standardized estimates were found to be sound. 
Table 2. Standardized regression weights estimates

\begin{tabular}{|ccc|c|}
\hline \multicolumn{2}{|c|}{$\begin{array}{l}\text { Observed variables loaded onto } \\
\text { their respective latent variables }\end{array}$} & Estimate \\
\hline DMS33 & $<---$ & DMS & .729 \\
DMS27 & $<---$ & DMS & .504 \\
DMS21 & $<---$ & DMS & .722 \\
DMS15 & $<---$ & DMS & .642 \\
DMS8 & $<---$ & DMS & .707 \\
DMS2 & $<---$ & DMS & .716 \\
DMS1 & $<---$ & DMS & .720 \\
OT34 & $<---$ & OT & .326 \\
OT28 & $<---$ & OT & .893 \\
OT22 & $<---$ & OT & .440 \\
OT16 & $<---$ & OT & .877 \\
OT9 & $<---$ & OT & .449 \\
OT3 & $<---$ & OT & .279 \\
JPA35 & $<---$ & JPA & .580 \\
JPA29 & $<---$ & JPA & .648 \\
JPA23 & $<---$ & JPA & .556 \\
JPA17 & $<---$ & JPA & .607 \\
JPA11 & $<---$ & JPA & .600 \\
JPA10 & $<---$ & JPA & .351 \\
JPA4 & $<---$ & JPA & .600 \\
SIE36 & $<---$ & SIE & .605 \\
SIE30 & $<---$ & SIE & .566 \\
SIE24 & $<---$ & SIE & .618 \\
SIE18 & $<---$ & SIE & .589 \\
SIE12 & $<---$ & SIE & .614 \\
SIE5 & $<---$ & SIE & .671 \\
TE37 & $<---$ & TE & .532 \\
TE31 & $<---$ & TE & .637 \\
TE25 & $<---$ & TE & .337 \\
TE19 & $<---$ & TE & .662 \\
TE6 & $<---$ & TE & .584 \\
DC32 & $<---$ & DC & .477 \\
DC26 & $<---$ & DC & .645 \\
DC20 & $<---$ & DC & .678 \\
DC13 & $<---$ & DC & .699 \\
SR38 & $<---$ & SR & .790 \\
SR14 & $<---$ & SR & .661 \\
SR7 & $<---$ & SR & .769 \\
\hline
\end{tabular}

Note: DMS = Demonstrating mutual support and trust; OT = Observing one another teaching; $\mathrm{JPA}=$ Joint planning and assessment; SIE $=$ Sharing ideas and expertise; $\mathrm{TE}=$ Teaching each other; $\mathrm{DC}=$ Developing curriculum together; $\mathrm{SR}=$ Sharing resources.

The covariances in the CFA model were all found to be statistically significant with critical ratio (C.R.) $>1.96$ using a significance level of .05. The correlations between all seven dimensions of teacher collegiality are shown in Table 3 indicating the standardized parameter 
estimates which ranged from .39 to .77 .

Table 3. Correlations between latent variables (subscales)

\begin{tabular}{|ccc|c|}
\hline \multicolumn{2}{|c|}{$\begin{array}{c}\text { Correlations between } \\
\text { latent variables }\end{array}$} & Estimate \\
\hline DMS & $<-->$ & OT & .441 \\
DMS & $<-->$ & JPA & .627 \\
DMS & $<-->$ & SIE & .754 \\
DMS & $<-->$ & TE & .770 \\
DMS & $<-->$ & DC & .457 \\
DMS & $<-->$ & SR & .492 \\
OT & $<-->$ & JPA & .570 \\
OT & $<-->$ & SIE & .455 \\
OT & $<-->$ & TE & .585 \\
OT & $<-->$ & DC & .535 \\
OT & $<-->$ & SR & .388 \\
JPA & $<-->$ & SIE & .707 \\
JPA & $<-->$ & TE & .714 \\
JPA & $<-->$ & DC & .637 \\
JPA & $<-->$ & SR & .419 \\
SIE & $<-->$ & TE & .758 \\
SIE & $<-->$ & DC & .492 \\
SIE & $<-->$ & SR & .430 \\
TE & $<-->$ & DC & .507 \\
TE & $<-->$ & SR & .449 \\
DC & $<-->$ & SR & .583 \\
\hline
\end{tabular}

Note: DMS = Demonstrating mutual support and trust; OT = Observing one another teaching; $\mathrm{JPA}=$ Joint planning and assessment; $\mathrm{SIE}=$ Sharing ideas and expertise; $\mathrm{TE}=$ Teaching each other; $\mathrm{DC}=$ Developing curriculum together; $\mathrm{SR}=$ Sharing resources.

\subsection{Assessment of model fit}

The goodness-of-fit (GOF) statistics were examined to verify the hypothesized model. Hair and colleagues (2006) recommend the use of one absolute fit index, one incremental, and the chi-square result as measures for the overall fit of the model. The $\chi^{2}$ value obtained was equal to 972.5 with 506 degrees of freedom and $p$-value was significant $(p<.001)$ showing that the two (observed sample and SEM estimated covariance) matrices were statistically different. Because the $\chi^{2}$ test is sensitive to both sample size and number of observed variables other fit indices were examined. 

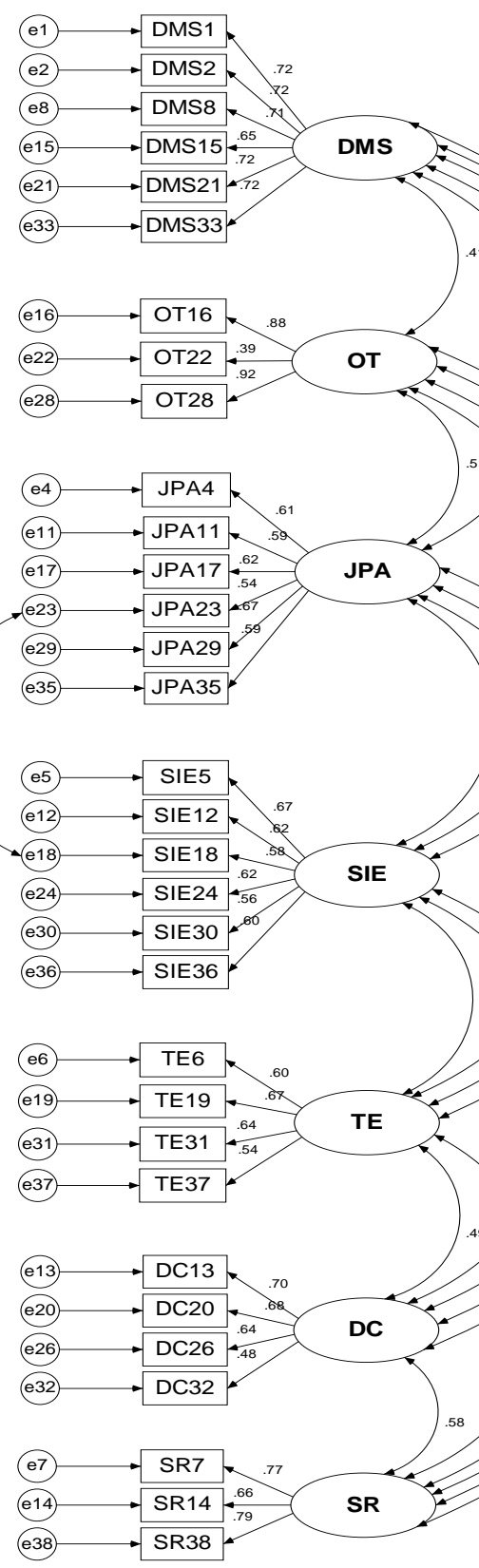

Figure 1. Modified model with standardized estimates

Note: DMS = Demonstrating mutual support and trust; OT = Observing one another teaching; JPA = Joint planning and assessment; $\mathrm{SIE}=$ Sharing ideas and expertise; $\mathrm{TE}=$ Teaching each other; $\mathrm{DC}=$ Developing curriculum together; $\mathrm{SR}=$ Sharing resources; $\mathrm{e}=$ error

The Root Mean Square Error of Approximation (RMSEA) and the Root Mean Square Residual (RMR) were used as absolute fit indices which consider values less than .07 and .08 respectively to demonstrate acceptable fit (Hair et al., 2006). Both RMSEA and RMR for the present model were found to be .05 indicating a good fit. The Comparative Fit Index (CFI) and the Tucker-Lewis Fit Index (TLI) were employed in this study as incremental fit indices which consider values greater than .90 associated with a model that fits well (Hair et al., 2006). The CFI and the TLI obtained from the analysis of current model were .89 and .88 
respectively. Both indicate a little less than adequate fit of the model to the data. To identify a model that better represented the sample data, the possible areas of misfit were assessed using modification indices (MIs) and residual moments.

The current model yielded eleven large standardized covariance residuals (i.e., $>2.58$ ) in the matrix. Four of these involved observed variable OT9 and three involved variable DMS27, indicating that these two variables (OT9 and DMS27) were associated with many other observed variables in the model, and were, therefore, candidates for deletion, as per Anderson and Gerbing's (1988) guidelines. Modification index (MI) values reveal cross-loadings and misspecified error covariances (where there is systematic error in item responses or item redundancy). The largest MIs indicate which parameters should be set free to improve fit maximally. In the current model, the parameter with the highest MI value was 'demonstrating mutual support and trust' (DMS), which cross-loaded onto the variable DC32 of 'developing curriculum together' (DC) subscale. Adding a new path from latent variable DMS to observed variable DC32 reduced the factor loading of DC32 from .51 to .38 onto its latent construct that is DC subscale. Therefore, this path was not added to the model. Another error covariance was suggested between one pair (e18 <--> e23) with a high MI. The presence of error covariance between this pair of observed variables might be due to high degree of content overlap. Therefore, an error covariance was added between e18 and e23. The modified CFA model with standardized estimates is shown in Figure 1.

Goodness-of-fit (GOF) statistics for the modified model are shown in Table 4 indicating that the overall GOF was dramatically improved. All GOF statistics either exceed or were just near the criteria suggested by Hair and his colleagues (2006). The modified measurement model yielded an overall $\chi^{2}$ value of $763.33, p<.001$ with CFI $=.93$, TLI $=.92$, and RMSEA $=.04 ;$ the $\chi^{2} / \mathrm{df}$ was 1.68 .

Table 4. Model fit indices for the modified model

\begin{tabular}{|l|cccccc|}
\hline & $\chi^{2}$ & $\chi^{2} / \mathbf{d f}$ & CFI & TLI & RMR & RMSEA \\
\hline $\begin{array}{l}\text { Criteria for } \\
\text { Good Fit }\end{array}$ & & $\leq 2.0$ & $\geq .90$ & $\geq .90$ & $\leq .08$ & $\leq .07$ \\
Fit Indices & 763.33 & 1.68 & .93 & .92 & .05 & .04 \\
\hline
\end{tabular}

\subsection{Reliability analysis of the final TCS}

Internal consistency (reliability) analysis was conducted using Cronbach's alpha for each of the subscales of the modified TCS. The final TCS (consisting of 32-items) addresses seven interpretable and internally consistent dimensions with subscales' internal consistency ranging from .71 to .85 . The Cronbach's alpha values of all subscales exceeded the cutoff value of .70, indicating that the final TCS met the acceptable standard of reliability analysis (Hair et al., 2006). The results of Cronbach's alpha reliability for the seven subscales of TCS are presented in Table 5. 
Table 5. Internal reliability of teacher collegiality scale

\begin{tabular}{|l|c|c|}
\hline Teacher collegiality subscales & $\begin{array}{c}\text { No. of } \\
\text { items }\end{array}$ & $\begin{array}{c}\text { Cronbach's } \\
\text { Alpha }\end{array}$ \\
\hline Demonstrating mutual support and trust (DMS) & 6 & .85 \\
Observing one another teaching (OT) & 3 & .74 \\
Joint planning and assessment (JPA) & 6 & .77 \\
Sharing ideas and expertise (SIE) & 6 & .78 \\
Teaching each other (TE) & 4 & .72 \\
Developing curriculum together (DC) & 4 & .71 \\
Sharing resources (SR) & 3 & .77 \\
\hline
\end{tabular}

\section{Discussion and conclusion}

The findings of the study indicated that teacher collegiality is a multi-dimensional concept defined as the presence of seven teacher behaviors in schools: (a) demonstrating mutual support and trust among teachers; (b) observing one another engage in the practice of teaching; (c) jointly planning and assessing teaching practices; (d) sharing ideas and expertise; (e) teaching each other; (f) developing curriculum together; and (g) sharing resources such as lesson plans, worksheets, and educational books.

The seven-dimensional concept of collegiality is one of the important contributions of this study and is of practical value in future educational research. These seven teacher collegial behaviors serve as concise and representative description of collegiality as practiced in Pakistani schools. This finding echoes others from previously conducted research in developed countries. Barth (1990) suggested four dimensions of collegiality in schools: talking about practice, observing each other, working on curriculum, and teaching each other. The current study supported these dimensions as well as added new dimensions to the concept of collegiality. They were demonstrating mutual support and trust, joint planning and assessment, sharing ideas and expertise, and sharing resources. Trust and support among colleagues are considered as important components of collegiality by many previous researchers (e.g., Barth, 1990; Bryk \& Schneider, 2003; Donaldson \& Sanderson, 1996; Friend \& Cook, 2000). Similarly, Fullan and Hargreaves (1991) suggested that teachers in highly collegial cultures are more likely to trust, value, and legitimize sharing expertise; seek advice; and help other teachers.

Ashton and Webb (1986) in their study emphasized that sharing resources and supplies, planning cooperatively, and developing a 'common sense of accomplishment' are crucial factors for establishing collegiality and collaboration among school teachers. According to Friend and Cook (1996), true collaboration is demonstrated when all team members feel that their contributions are valued, they share decision making, and sense they are respected. Friend and Cook (1996) further claim that collaboration among teachers is based on sharing resources and knowledge. Lieberman and Miller (1999) states that professional collegial communities are built 'when principals and staff enhance their resources by reinforcing a climate of support and respect for teachers' work and by pursuing a continuous cycle of innovation, feedback and redesign in curriculum, instruction and assessment' (p. 62). 
John-Steiner, Weber, and Minnis (1998) stated that collaboration not only includes planning, deciding, and acting jointly but also involves thinking together. According to them, 'in a true collaboration, there is a commitment to shared resources, power, and talent: no individual's point of view dominates, authority for decisions and actions resides in the group, and work products reflect a blending of all participants' contributions... (p. 776). Ross, Ertmer, and Johnson (2001) suggested that collaboration among teachers provides a structure for sharing ideas and practices, and establishes a network of support. Russell (2002) explained that collaboration is based on shared goals, shared vision, a climate of trust, respect, comprehensive planning, and shared risks. According to Hartnell-Young (2006), teachers working in a collegial environment talk about learning processes, plan activities and curriculum, and invite others into their classrooms.

The additional dimensions of teacher collegiality generated by the current analysis are supported by the existing literature. The results of the exploratory and confirmatory factor analysis suggest that TCS is an instrument that will prove useful in measuring teacher collegiality in Pakistan. Based on Cronbach's alpha values, the instrument has high reliability; thus, can be used in further analyses.

However, the current study has some limitations. The items for this instrument were mostly generated from previous research studies. Furthermore, the validation of instruments requires a large sample. The small sample size used for the preliminary EFA could be a limitation. To address this limitation, TCS was further validated using CFA on a new sample. This study uses a sample that was limited to the teachers of public secondary schools in Pakistan. Therefore, the generalizability of the results may be a limitation. The findings may be generalized to countries with similar teacher culture. Future studies to validate this instrument in other nations and cultures contexts will strengthen its value as a research instrument.

One of the major contributions of this study is that it uses quantitative approach to identify factors of teacher collegiality. The use of robust analytical techniques that is EFA and CFA to validate the instrument is the strength of this study. Most of the previously conducted studies on collegiality were based on case studies. Moreover, studies exploring the concept of collegiality and identifying its major dimensions were mostly conducted in the United States and other developed countries. The current study explored the concept of teacher collegiality in a developing country.

The results of this study provide insight to school administrators and teachers in focusing on different dimensions of collegiality in order to strengthen interpersonal relations among teaching staff.

\section{Acknowledgement}

Special thanks to Prof. Dr. Elizabeth O' Sullivan from the University of Maryland, US for her time and effort in improving this article.

\section{References}

Abdullah, J. (2009). Lowering teacher attrition rates through collegiality. Academic 
http://www.academicleadership.org/emprical_research/531.shtml

Anderson, J. C., \& Gerbing, D. W. (1988). Structural equation modeling in practice: A review and recommended two-step approach. Psychological Bulletin, 103 (3), 411-423. http://dx.doi.org/10.1037/0033-2909.103.3.411

Andrews, D., \& Lewis, M. (2002). The experience of a professional community: Teachers developing a new image of themselves and their workplace. Educational Research, 44 (3), 237-254. http://dx.doi.org/10.1080/00131880210135340

Ashton, P. T., \& Webb, R. B. (1986). Making a difference: Teachers' sense of efficacy and student achievement. New York, NY: Longman.

Barth, R. S. (1990). Improving schools from within. San Francisco, CA: Jossey-Bass.

Barth, R. S. (2001). Learning by heart. San Francisco, CA: Jossey-Bass.

Brownell, M. T., Adams, A., Sindelar, P., Waldron, N., \& Vanhover, S. (2006). Learning from collaboration: The role of teacher qualities. Exceptional Children, 72 (2), 169-187.

Brownell, M. T., Yeager, E., Rennells, M. S., \& Riley, T. (1997). Teachers working together: What teacher educators and researchers should know. Teacher Education and Special Education, 20 (4), 340-359. http://dx.doi.org/10.1177/088840649702000405

Bruffee, K. A. (1999). Collaborative learning: Higher education, interdependence, and the authority of knowledge (2nd ed.). Baltimore, MD: The Johns Hopkins University Press.

Bryk, A. S., \& Schneider, B. (2003). Trust in schools: A core resource for school reform. Educational Leadership, 60 (6), 40-45.

Campbell, P., \& Southworth, G. (1992). Rethinking collegiality: Teachers' views. In N. Bennett, M. Crawford, \& C. Riches (Eds.), Managing change in education: Individual and organizational perspectives (pp. 61-79). London, UK: Paul Chapman.

Donaldson, G.., \& Sanderson, D. (1996). Working together in schools: A guide for educators. Thousand Oaks, CA: Corwin Press.

DuFour, R. (2004). What is a "professional learning community?" Educational Leadership, $61(8), 6-11$.

Friend, M., \& Cook, L. (1996). Interactions: Collaborative skills for school professionals (2nd ed.). White Plains, NY: Longman.

Friend, M., \& Cook, L. (2000). Interactions: Collaboration skills for school professionals (3rd ed.). White Plains, NY: Longman.

Fullan, M. G.., \& Hargreaves, A. (1991). What's worth fighting for? Working together for your school. Ontario, CAN: Ontario Public Schools Teachers' Federation.

Gable, R., Mostert, M., \& Tonelson S. (2004). Assessing professional collaboration in schools: 
Knowing what works. Preventing School Failure, $48 \quad$ (3), 4-9. http://dx.doi.org/10.3200/PSFL.48.3.4-8

Goddard, Y. L., Goddard, R. D., \& Tschannen-Moran, M. (2007). A theoretical and empirical investigation of teacher collaboration for school improvement and student achievement in public elementary schools. Teachers College Record, 109 (4), 877-896.

Goldenberg, C. (2004). Successful school change: Creating settings to improve teaching and learning. New York, NY: Teachers College Press.

Goodlad, J. I. (1984). A place called school: Prospects for the future. New York, NY: McGraw-Hill.

Gossen, D., \& Anderson, J. (1995). Creating the conditions: Leadership for quality schools. Chapel Hill, NC: New View.

Hair, J. F. Jr., Black, W. C., Babin, B. J., Anderson, R. E., \& Tatham, R. L. (2006). Multivariate data analysis (6th ed.). Upper Saddle River, NJ: Pearson Prentice Hall.

Hargreaves, A. (1994). Changing teachers, changing times: Teachers'work and culture in the postmodern age. London, UK: Cassell.

Hartnell-Young, E. (2006). Teachers' roles and professional learning in communities of practice supported by technology in schools. Journal of Technology and Teacher Education, 14 (3), 461-480.

Heider, K. L. (2005). Teacher isolation: How mentoring programs can help. Current Issues in Education, 8 (14). [Online] Available: http://cie.ed.asu.edu/volume8/number14/

Hopkins, D., Beresford, J., \& West, M. (1998). Creating the conditions for classroom and teacher development, Teachers and Teaching: Theory and Practice, 4 (1), 115-141.

Jarzabkowski, L. M. (1999). Commitment and compliance: Curious bedfellows in teacher collaboration. Paper presented at the Australian Association for Research in Education and New Zealand Association for Research in Education joint Conference (Nov 29-Dec 2)., Melbourne Convention Center, Melbourne.

Jarzabkowski, L. M. (2002). The social dimensions of teacher collegiality. Journal of Educational Enquiry, 3 (2), 1-20.

Jarzabkowski, L. M. (2003). Teacher collegiality in a remote Australian school. Journal of Research in Rural Education, 18 (3), 139-144.

Johnson, S. M. (1990). Teachers at work: Achieving success in our schools. New York, NY: Basic Books.

John-Steiner, V., Weber, R., \& Minnis, M. (1998). The challenge of studying collaboration. American Education Research Journal, 35 (4), 773-783. http://dx.doi.org/10.2307/1163466

Joyce, B. (2004). How are professional learning communities created? Phi Delta Kappan, 86 (1), 76-83. 
Kaiser, H. F. (1974). An index of factorial simplicity. Psychometrika, 39 (1), 31-36. http://dx.doi.org/10.1007/BF02291575

Knapp, M. S. (2003). Professional development as a policy pathway. Review of Research in Education, 27 (1), 109-157. http://dx.doi.org/10.3102/0091732X027001109

Lieberman, A. (1986). Rethinking school improvement. New York, NY: Teachers College Press.

Lieberman, A., \& Miller, L. (1990). Teacher development in professional practice and school. Teachers College Record, 92 (1), 105-122.

Lieberman, A., \& Miller, L. (1999). Teachers: Transforming their world and their work. New York: Teachers College Press.

Little, J. W. (1982). Norms of collegiality and experimentation: Workplace conditions of school success. American Educational Research Journal, 19 (3), 325-340.

Little, J. W. (1990). The persistence of privacy: Autonomy and initiative in teachers' professional relations. Teachers College Record, 91 (4), 509-536.

Little, J. W. (1999). Colleagues of choice, colleagues of circumstance: A response to M Fielding. The Australian Educational Researcher, 26 (2), 35-43. http://dx.doi.org/10.1007/BF03219693

Little, J. W., Gearhart, M., Curry, M., \& Kafta, J. (2003). Looking at student work for teacher learning, teacher community and school reform. Phi Delta Kappan, 85 (3), 184-192.

Maslach, C., \& Leiter M. P. (1999) Teacher burnout: A research agenda. In R. Vandenberghe, \& A. M. Huberman (Eds.), Understanding and preventing teacher burnout: A sourcebook of international research and practice (pp. 295-303). Cambridge: Cambridge University Press. http://dx.doi.org/10.1017/CBO9780511527784.021

McLaughlin, M. W. (1993). What matters most in teachers' workplace contexts? In J. W. Little, \& M. W. McLaughlin (Eds.), Teachers'work: Individuals, colleagues and contexts (pp. 79-103). New York, NY: Teachers College Press.

Nias, J. (1998). Why teachers need their colleagues: A developmental perspective. In A. Hargreaves, A. Lieberman, M. Fullan, \& D. Hopkins (Eds.), International handbook of educational change (pp. 1257-1271). Dordrecht, The Netherlands: Kluwer.

Nias, J. (1999) Teachers' moral purposes: Stress, vulnerability, and strength. In R. Vandenberghe, \& A. M. Huberman (Eds.), Understanding and preventing teacher burnout: a sourcebook of international research and practice (pp. 223-237). Cambridge: Cambridge University Press. http://dx.doi.org/10.1017/CBO9780511527784.015

Numeroff, D. (2005). Teacher collegiality and collaboration in exemplary high school math departments. Doctoral dissertation, Florida Atlantic University, AAT 3162664.

Pugach, M. C., \& Johnson, L. J. (1995). Collaborative practitioners collaborative schools. 
Denver, CO: Love Publishing.

Retallick, J., \& Butt, R. (2004). Professional well-being and learning: A study of teacher-peer workplace relationships. Journal of Educational Enquiry, 5 (1), 85-99.

Rosenholtz, S. J. (1989). Workplace conditions that affect teacher quality and commitment: Implications for teacher induction programs. The Elementary School Journal, 89 (4), 421-439. http://dx.doi.org/10.1086/461584

Ross, E., Ertmer, P., \& Johnson, T. (2001). Technology integration and innovative teaching practices: A staff development model for facilitating change. Proceedings of the National Convention of Association for Educational Communications and Technology, 24, 870-882.

Russell, S. (2002). Teachers and library media specialists: Collaborative relationships. Teacher Library Media Specialist, 29 (5), 35-38.

Schmoker, M. (2004). Tipping point: From feckless reform to substantive instructional improvement. Phi Delta Kappan, 85 (6), 424-432.

Shachar, H., \& Shmuelevitz, H. (1997). Implementing cooperative learning, teacher collaboration and teacher's sense of efficacy in heterogeneous junior high schools. $\begin{array}{lllll}\text { Contemporary Educational } & \text { Psychology, } & 22 & \text { (1), }\end{array}$ http://dx.doi.org/10.1006/ceps.1997.0924

Smyth, J. (1991). International perspectives on teacher collegiality: A labour process discussion based on the concept of teachers' work. British Journal of Sociology of Education, 12 (3), 323-346.

Stevens, J. (1996). Applied multivariate statistics for the Social Sciences (3rd ed.). Mahwah, NJ: Lawrence Erlbaum Associates.

Telford, H. (1996). Transforming schools through collaborative leadership. London, UK: Falmer Press.

The American Heritage Dictionary of the English language, 4th ed. (2000). [Online] Available:

http://www.bartleby.com/cgi-bin/texis/webinator/ahdsearch?search_type=enty\&query=collab oration $\& d b=$ ahd $\&$ Submit $=$ Search

Tschannen-Moran, M. (2001). Collaboration and the need for trust. Journal of Educational Administration, 39 (4), 308-331. http://dx.doi.org/10.1108/EUM0000000005493

Wang, J., Odell, S. J., \& Schwille, S. A. (2008). Effects of teacher induction on beginning teachers' teaching: A critical review of the literature. Journal of Teacher Education, 59 (2), 132-152. http://dx.doi.org/10.1177/0022487107314002

Webster's College Dictionary. (1997). New York, NY: Random House.

Wheelan, S., \& Tilin, F. (1999). The relationship between faculty group development and school productivity. Small Group Research, 30 (1), 59-81. 
http://dx.doi.org/10.1177/104649649903000104

Williams, A., Prestage, S., \& Bedward, J. (2001). Individualism to Collaboration: the significance of teacher culture to the induction of newly qualified teachers. Journal of Education for Teaching, 27 (3), 253-267. http://dx.doi.org/10.1080/02607470120091588

Woods, A. M., \& Weasmer, J. (2002). Maintaining job satisfaction: Engaging professionals as active participants. The Clearing House, 75 (4), 186-189. http://dx.doi.org/10.1080/00098650209604928

Zahorik, J. A. (1987). Teachers' collegial interactions: An exploratory study. The Elementary School Journal, 87 (4), 385-396. http://dx.doi.org/10.1086/461503

Zhao, Y., Pugh, K., Sheldon, S., \& Byers, J. (2002). Conditions for classroom technology innovations. Teachers College Record, 104 (3), 482-515.

Note

Note 1. In Pakistan, schools are separated by gender

\section{Copyright Disclaimer}

Copyright reserved by the author(s).

This article is an open-access article distributed under the terms and conditions of the Creative Commons Attribution license (http://creativecommons.org/licenses/by/3.0/). 